\title{
Remediation of Lead and Nickel Contaminated Soil Using Nanoscale Zero-Valent Iron (nZVI) Particles Synthesized Using Green Leaves: First Results
}

\author{
Nimita Francy ${ }^{1}$, Subramanian Shanthakumar ${ }^{1} \mathbb{D}$, Fulvia Chiampo ${ }^{2, * \mathbb{D}}$ \\ and Yendaluru Raja Sekhar ${ }^{3}$ D \\ 1 Department of Environmental and Water Resources Engineering, School of Civil Engineering, \\ Vellore Institute of Technology (VIT), Vellore 632014, India; nimitafrancy@gmail.com (N.F.); \\ shanthakumar.s@vit.ac.in (S.S.) \\ 2 Department of Applied Science and Technology, Politecnico di Torino, Corso Duca degli Abruzzi 24, \\ 10129 Torino, Italy \\ 3 Department of Thermal and Energy Engineering, School of Mechanical Engineering, \\ Vellore Institute of Technology (VIT), Vellore 632014, India; rajasekhar.y@vit.ac.in \\ * Correspondence: fulvia.chiampo@polito.it; Tel.: +39-011-090-4685
}

Received: 16 October 2020; Accepted: 12 November 2020; Published: 13 November 2020

\begin{abstract}
Nanoscale zero-valent iron (nZVI) particles have proved to be effective in the remediation of chlorinated compounds and heavy metals from contaminated soil. The present study aimed to analyze the performance of nanoparticles synthesized from low-cost biomass (green leaves) as chemical precursors, namely Azadirachta indica (neem) and Mentha longifolia (mint) leaves. These leaves were chosen because huge amounts of them are present in the region of Vellore. These nanoparticles were used to remove lead and nickel from contaminated soil. Characterization of nZVI particles was conducted using the Scanning Electron Microscope (SEM), Transmission Electron Microscope (TEM), and Brunauer-Emmett-Teller isotherm (BET) techniques. Remediation was performed on two different soil samples, polluted with lead or nickel at an initial metal concentration around $250 \mathrm{mg} / \mathrm{kg}$ of soil. The results revealed that after 30 days, the lead removal efficiency with $0.1 \mathrm{~g}$ of nZVI particles/kg of soil was $26.9 \%$ by particles synthesized using neem leaves and $62.3 \%$ by particles synthesized using mint leaves. Similarly, nickel removal efficiency with $0.1 \mathrm{~g}$ of particles $/ \mathrm{kg}$ of soil was $33.2 \%$ and $50.6 \%$, respectively, by particles using neem and mint leaves. When the nanoparticle concentration was doubled, $\mathrm{Pb}$ and $\mathrm{Ni}$ removal improved, with similar trends obtained at a lower dosage $(0.1 \mathrm{~g}$ of particles $/ \mathrm{kg}$ of soil). These first results evidenced that: (1) the nZVI particles synthesized using green leaves had the potential to remove $\mathrm{Pb}$ and Ni from contaminated soil; (2) the neem-derived particles gave better $\mathrm{Ni}$ removal efficiency than $\mathrm{Pb}$ one; (3) the mint-derived particles showed better $\mathrm{Pb}$ removal efficiency than Ni one; (4) the highest removal efficiency for both metals was achieved with the mint-derived particles; (5) double higher dosage did not greatly improve the results.
\end{abstract}

Keywords: neem; mint; nZVI synthesis; lead; nickel; soil remediation

\section{Introduction}

The discharge of industrial waste into the environment causes the accumulation of heavy metals in water and soil. Lead $(\mathrm{Pb})$ and nickel $(\mathrm{Ni})$ are two heavy metals present in the environment due to industrial activities. The average concentration of $\mathrm{Pb}$ on surface soil worldwide is approximately $32 \mathrm{mg} / \mathrm{kg}$ of soil [1], and its excessive amount is hazardous to living organisms and the environment [2]. Lead toxicity 
affects every part of the human body, mainly the nervous system and kidney. Children exposed to high $\mathrm{Pb}$ concentrations for a long time are likely to have impaired development [3].

The presence of $\mathrm{Pb}$ in high concentrations can affect joints of the human body and lead to miscarriage in pregnant women [4]. The primary sources of $\mathrm{Pb}$ discharge into the environment are mostly fertilizer, biosolids, metal mining, battery, and paint industries [5]. Generally, fertilizers used for supplying nitrogen-phosphorous-potassium (NPK) to soil contain lead and cadmium (Cd) as component elements [6]. Biosolids can contain $\mathrm{Pb}$, depending on their industrial source. Pb concentration in soil equal to $300 \mu \mathrm{g} / \mathrm{kg}$ of soil is evaluated as a threshold without substantial risk for intake by humans [7].

In the metal mining industry, a large quantity of ores is extensively mined, causing potential risk to the environment by polluting the soil. Contamination of $\mathrm{Ni}$ to the environment is mostly from electroplating, welding, refining, battery, paint, and porcelain production industrial effluents [8-10]. Some of the significant health issues caused by $\mathrm{Ni}$ are nausea, gastric problems, and bronchitis [11]. The average concentration of $\mathrm{Ni}$ on the Earth's surface is $20 \mathrm{ppm} \mathrm{[12],} \mathrm{whereas} \mathrm{the} \mathrm{range} \mathrm{of} \mathrm{Ni}$ concentration in soil is between 0.2 and $450 \mathrm{ppm}$ [13].

The leaching of heavy metals due to rainfall causes the contamination of the surface, subsurface soil, and groundwater, affecting the food chain by bioaccumulation in each trophic level [14]. Numerous techniques have been adopted in the decontamination of heavy metals from soil, such as phytoremediation, phytoextraction, soil washing, adsorption, and nanoremediation [6]. Among the techniques, nanoremediation is an effective system as it contains smaller-sized active nanoparticles, with a large specific surface area [15]. Among these, nanoscale zero-valent iron (nZVI) particles are nanoparticles $(1-100 \mathrm{~nm})$ containing zero-valent iron, obtained from different kinds of chemical synthesis. As for other pollutants, the mechanisms for the removal of heavy metals by nZVI particles are adsorption, reduction/oxidation, precipitation, and coprecipitation.

Pasinszki and Krebsz [16] recently published a review on the synthesis and application of nZVI nanoparticles. This review constitutes one of the most comprehensive and prominent reviews on the use of these nanoparticles, completed with an interesting section on the particle toxicity.

The type and nature of the remediation process undertaken by nZVI mainly depend on the electronegativity of the contaminants to be removed [17]. Literature data show that: (a) nZVI with $1 \%$ hydrogen peroxide is effective for the decontamination of pentachlorophenol [18]; (b) $\mathrm{MgO} \mathrm{TiO}_{2}$, and $\mathrm{ZnO}$ nanoparticles at $1 \%$ proved to provide good removal of chromium from soil contaminated with leather factory waste [19]; (c) the contact particle air is deleterious due to oxide formation, and preparation of stable nanoparticles was proposed with different chelating agents [20]. Hence, nanoremediation using nZVI particles is an emerging technique for wastewater decontamination and soil remediation, with more questions remaining.

Regarding water/wastewater treatment, nanoparticle application has received wider attention and development than soil remediation due to the easiness of contact water particles.

Valipour et al. [21] conducted studies to evaluate remediation characteristics of two phosphorus amendments, triple superphosphate (TSP) and phosphate rock (PR), to reduce $\mathrm{Pb}, \mathrm{Cd}, \mathrm{Ni}$, and $\mathrm{Cu}$ contamination in four artificially contaminated, mainly calcareous, soils. Though TSP reduced the $\mathrm{Pb}$ and $\mathrm{Cd}$ presence, it increased the availability of Ni. PR did not show any reduction of metal contamination in calcareous soils. Yadegari [22] studied the influence on growing purslane plants to reduce the contamination of heavy metals such as $\mathrm{Ni}$ and $\mathrm{Cd}$. He conducted pot experiments by spiking $\mathrm{Ni}(0,30,60$, and $120 \mathrm{mg} / \mathrm{kg}$ of soil) and $\mathrm{Cd}(0,10,20$, and $40 \mathrm{mg} / \mathrm{kg}$ of soil) into soil for two seasons. Heavy metals in the soil had a compelling effect on the morphological and physiological characteristics of purslane. Higher concentrations of metal contamination resulted in a decrease of morphological and physiological characteristics and a stronger influence of Cd. De Gisi et al. [23] used commercially available nZVI Nanofer $25 \mathrm{~S}$ to treat contaminated marine sediments polluted by heavy metals. They conducted experimental runs on soil particles $<5 \mathrm{~mm}$ and two dosages, i.e., low dosage $(2,3$, and $4 \mathrm{~g}$ nZVI per kg of Suspended Solids) and high dosage $(5,10$, and $20 \mathrm{~g}$ nZVI per $\mathrm{kg}$ of Suspended Solids). They concluded that the average dosages of nZVI could effectively reduce 
heavy metal contamination in sediments. Vasarevičius et al. [24] conducted experimental runs to remove $\mathrm{Cd}, \mathrm{Cu}, \mathrm{Ni}$, and $\mathrm{Pb}$ contamination in spiked soil samples using commercial nZVI particles. They evaluated the remediation levels for single and multiple metals (mixtures of $\mathrm{Cu}, \mathrm{Ni}, \mathrm{Pb}$ and $\mathrm{Cd}, \mathrm{Cu}, \mathrm{Ni}, \mathrm{Pb})$ using different doses $(0 \%, 0.85 \%, 1.7 \%, 2.55 \%$, and $5.1 \%$ by weight) of nZVI particles. The leaching procedure was adopted to determine immobilization efficiency for each specific metal and nZVI dose. Their results showed effective metal removal and metal stabilization at higher dosages for all the samples.

In the present study, nanoscale zero-valent iron (nZVI) particles were chemically synthesized using neem and mint leaves to remove lead and nickel from two soils. These leaves were chosen because huge amounts of them are present in the region of Vellore.

The preliminary results are promising and worth future studies to better understand their performance and find optimal conditions for their application at a larger scale.

\section{Materials and Methods}

\subsection{Synthesis of $n Z V I$ Particles}

Synthesis of nZVI particles using FeSO $\mathrm{F}_{4} \cdot 7 \mathrm{H}_{2} \mathrm{O}$ and $\mathrm{NaBH}_{4}$ : For nZVI synthesis, $4.17 \mathrm{~g}$ of $\mathrm{FeSO}_{4} \cdot 7 \mathrm{H}_{2} \mathrm{O}$ in $150 \mathrm{~mL}$ of water and $3.72 \mathrm{~g}$ of EDTA in $100 \mathrm{~mL}$ of water were mixed with $2.87 \mathrm{~g}$ of $\mathrm{NaBH}_{4}$ in $100 \mathrm{~mL}$ of distilled water in a stirred closed flask for $60 \mathrm{~min}$ and purged with nitrogen to achieve black color precipitates. These particles were filtered, washed with ethanol thrice, and filtered again [20].

Synthesis of nZVI particles using neem and mint leaves: Synthesis using Azadirachta indica (neem) and Mentha longifolia (mint) leaves was identical for each kind of leaf and involved the following procedure: (i) $10 \mathrm{~g}$ of leaves were cleaned, washed, dried, chopped and grounded; (ii) the leaves were then heated to $50{ }^{\circ} \mathrm{C}$ within $20 \mathrm{~mL}$ of distilled water for $10 \mathrm{~min}$; (iii) $20 \mathrm{~mL}$ of each leaf extract was mixed with $20 \mathrm{~mL}$ of $0.001 \mathrm{M} \mathrm{FeCl}_{3} \cdot 6 \mathrm{H}_{2} \mathrm{O}$ in a stirred closed flask for $60 \mathrm{~min}$ and purged with nitrogen. During this stage, $1 \%$ of polyvinyl alcohol and $1 \%$ of chitosan were added to stabilize the particles; (iv) the obtained black color particles were filtered and (v) dried at $50{ }^{\circ} \mathrm{C}$ for $12 \mathrm{~h}$ [25].

\subsection{Characterization of $n Z V I$ Particles}

Each kind of nanoparticles was studied using the Scanning Electron Microscope (SEM), Transmission Electron Microscope (TEM), and Brunauer-Emmett-Teller isotherm (BET). SEM analysis was performed to examine the surface morphology, whereas the shape and the approximate structure could be achieved from TEM analysis. BET analysis was useful to determine the specific surface area.

\subsection{Soil and its Original Characteristics}

Two soil samples (A and B) of $1 \mathrm{~kg}$ each were collected from different locations in VIT University, Vellore. The samples were cleaned, dried, and sieved through a $2 \mathrm{~mm}$ sieve. The $\mathrm{pH}$ and electrical conductivity of each soil sample were determined as per the Bureau of Indian Standards [26,27]. Specific gravity [28] (ASTM-D854, 2014), water content [29] (ASTM-D4959, 2016), organic content [30] (ASTM-D2974, 2014), and particle size analysis [31] (ASTM-D422, 2007) of the soil samples were conducted.

The initial lead and nickel content of the soil was determined by the Atomic Absorption Spectroscopy (AAS) technique. The soil extract was prepared with $5 \mathrm{~g}$ of soil in $50 \mathrm{~mL}$ of $1 \mathrm{M} \mathrm{HNO}_{3}$ and placed in the shaker for $60 \mathrm{~min}$ to ascertain complete mixing. The supernatant obtained was used for AAS analysis.

The same method was used to monitor the experimental runs to measure the residual concentration of lead or nickel in the soil.

\subsection{Pollution of Soil Samples and Nanoparticle Addition}

The heavy-metal-contaminated soil was prepared by adding $\mathrm{Ni}$ or Pb solution to the soil. For nickel, a solution was prepared by dissolving $4.785 \mathrm{~g}$ of $\mathrm{NiSO}_{4} \cdot 7 \mathrm{H}_{2} \mathrm{O}$ in $1 \mathrm{~L}$ of double-distilled water. Similarly, 
the lead solution was made by dissolving $1.615 \mathrm{~g}$ of $\mathrm{Pb}\left(\mathrm{NO}_{3}\right)_{2}$ in $1 \mathrm{~L}$ of double-distilled water. Spiking of the soil was conducted to achieve a target metal concentration around $250 \mathrm{mg} / \mathrm{kg}$ of soil and, at the same time, considering the solution water content as a contribution to meet the soil field capacity. The initial heavy metal concentration was constantly verified by analysis.

The addition of nanoparticles was conducted on parts of the initial sample to optimize the distribution. Each soil sample and nanoparticle dose were divided into five parts. Then, each soil part was mixed with one particle part. Finally, these 5 quotas were transferred to a $1 \mathrm{~L}$ beaker and monitored for 30 days. Two dosages were tested, namely 0.1 and $0.2 \mathrm{~g} / \mathrm{kg}$ of soil.

\subsection{Remediation of Soil Samples}

The remediation of heavy-metal-contaminated soil was studied at room temperature for 30 days. Along each test period, $\mathrm{Pb}$ and $\mathrm{Ni}$ residual concentration was monitored by AAS analysis on the extract derived from the $5 \mathrm{~g}$ sample leaching with $\mathrm{HNO}_{3}$ (see Section 2.3), and the effect of concentration and time on soil was studied.

All the analyses were replicated twice. The average results will be shown without error bars and standard deviations because two replicates cannot support a reliable statistical analysis.

The residual concentration at time $t=30$ days was used to calculate the removal efficiency:

$$
\text { Heavy metal removal } \%=\frac{C_{i}-C_{f}}{C_{i}} \times 100
$$

where: $C_{i}=$ initial heavy metal concentration ( $\mathrm{mg} / \mathrm{kg}$ of soil), $\mathrm{C}_{\mathrm{f}}=$ final heavy metal concentration ( $\mathrm{mg} / \mathrm{kg}$ of soil).

\section{Results}

\subsection{Characteristics of $n Z$ VI Particles}

BET analysis: The surface area of the chemically synthesized nZVI particles was $15.2 \mathrm{~m}^{2} / \mathrm{g}$, and for the particles synthesized using neem and mint leaves, the surface area was $6.2 \mathrm{~m}^{2} / \mathrm{g}$ and $13.0 \mathrm{~m}^{2} / \mathrm{g}$, respectively.

SEM analysis: The SEM images are presented in Figure 1a,b (chemically synthesized nanoparticles), Figure 1c,d (nanoparticles synthesized using neem leaves), and Figure 1e,f (nanoparticles synthesized using mint leaves). The images show that the particles are spherical and subjected to agglomeration.

TEM analysis: The TEM images are shown in Figure 2. It can be observed that the particles derived from leaf extracts are agglomerated. The color difference between the core and outer layer of the nanoparticle shows that the chemically synthesized nanoparticle (Figure 2a,b) is more subjected to oxidation than those synthesized using leaves (Figure 2c-f).

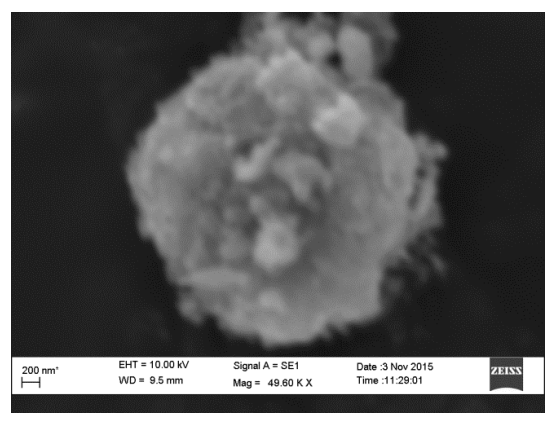

(a)

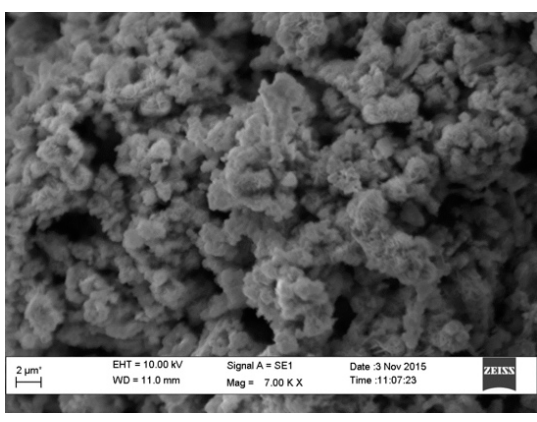

(b)

Figure 1. Cont. 


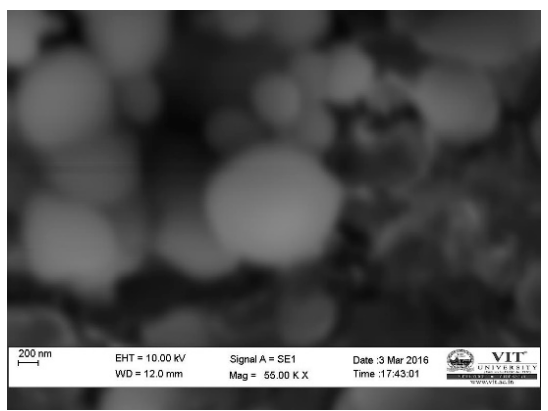

(c)

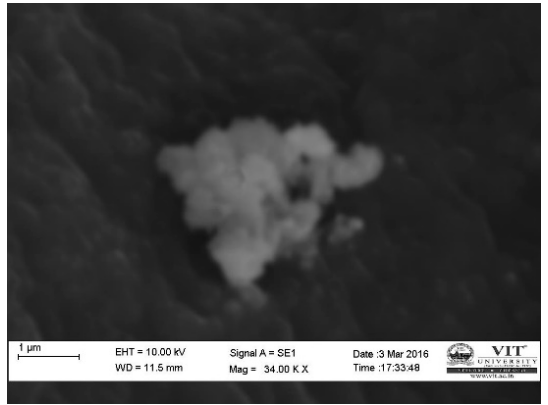

(e)

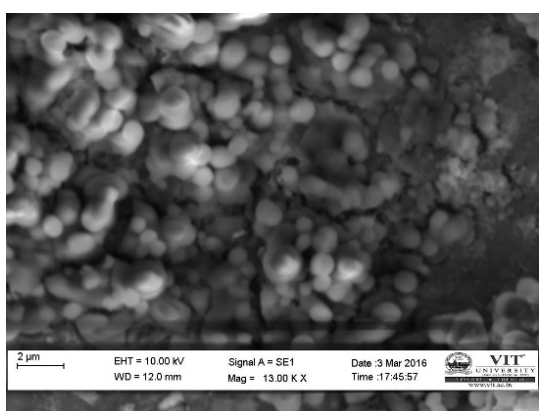

(d)

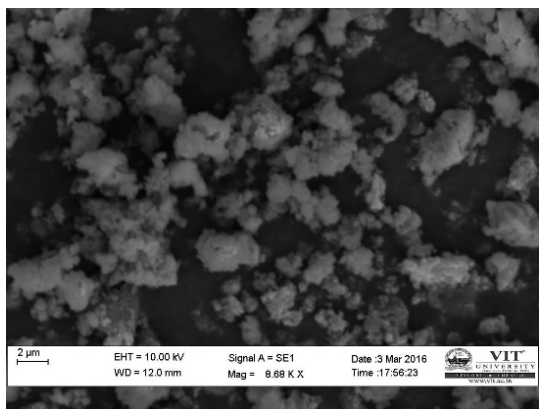

(f)

Figure 1. SEM image of nanoscale zero-valent iron (nZVI) particles: (a,b) from chemical synthesis; (c,d) using neem leaves; (e,f) using mint leaves.

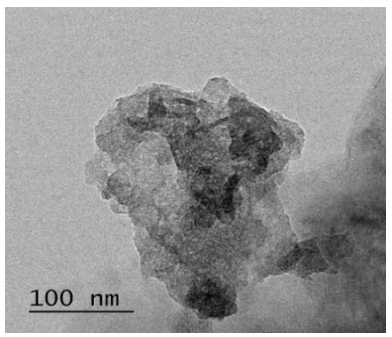

(a)

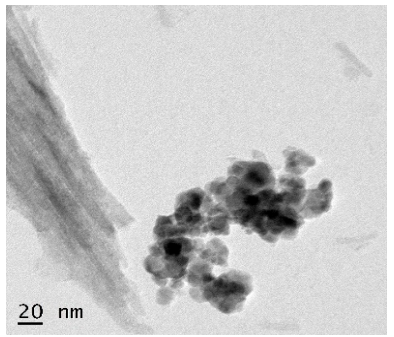

(c)

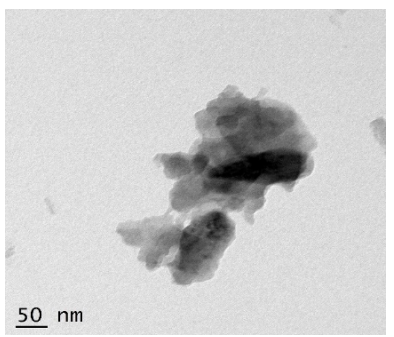

(e)

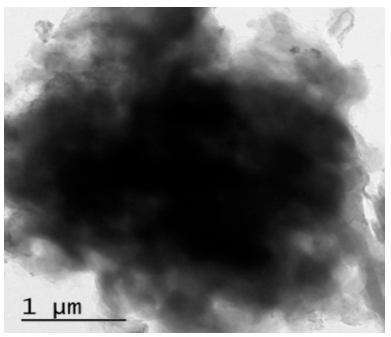

(b)

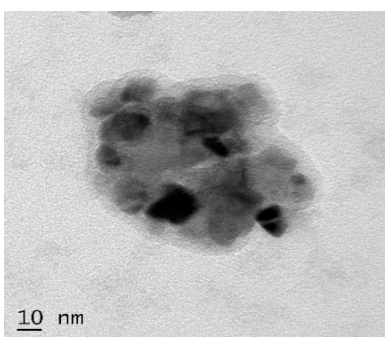

(d)

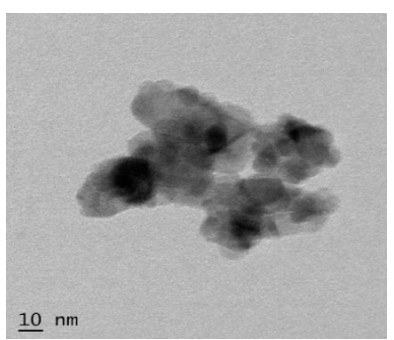

(f)

Figure 2. TEM image of nZVI particles: $(\mathbf{a}, \mathbf{b})$ chemically synthesized; $(\mathbf{c}, \mathbf{d})$ using neem leaves; $(\mathbf{e}, \mathbf{f})$ using mint leaves. 


\subsection{Soil Characteristics}

The initial characteristics of the collected soil samples are presented in Table 1. Both soils were categorized as coarse-graded, sandy soil and contained a trace of lead and nickel, as demonstrated by their low concentration.

Table 1. Initial characteristics of the soil samples.

\begin{tabular}{ccc}
\hline Characteristics & Soil A & Soil B \\
\hline Soil type & Coarse-graded, sandy soil & Coarse-graded, sandy soil \\
pH & 6.65 & 5.32 \\
Conductivity $(\mathrm{mS} / \mathrm{cm})$ & 1.12 & 0.98 \\
Water content $(\%)$ & 13.7 & 12.9 \\
Specific gravity & 2.98 & 3.07 \\
Organic content $(\%$ by weight) & 2.78 & 4.94 \\
Lead concentration $(\mathrm{mg} / \mathrm{kg}$ of soil) & 0.245 & 0.234 \\
Nickel concentration $(\mathrm{mg} / \mathrm{kg}$ of soil) & 0.201 & 0.267 \\
\hline
\end{tabular}

\subsection{Remediation of Contaminated Soil}

\subsubsection{Remediation by Chemically Synthesized nZVI Particles}

The remediation monitoring of lead and nickel using chemically synthesized nZVI particles is presented in Figure 3, where the residual lead and nickel concentration at the dosage of $0.1 \mathrm{~g}$ of nanoparticle $/ \mathrm{kg}$ of soil added to each contaminated soil sample (A and B) is presented.

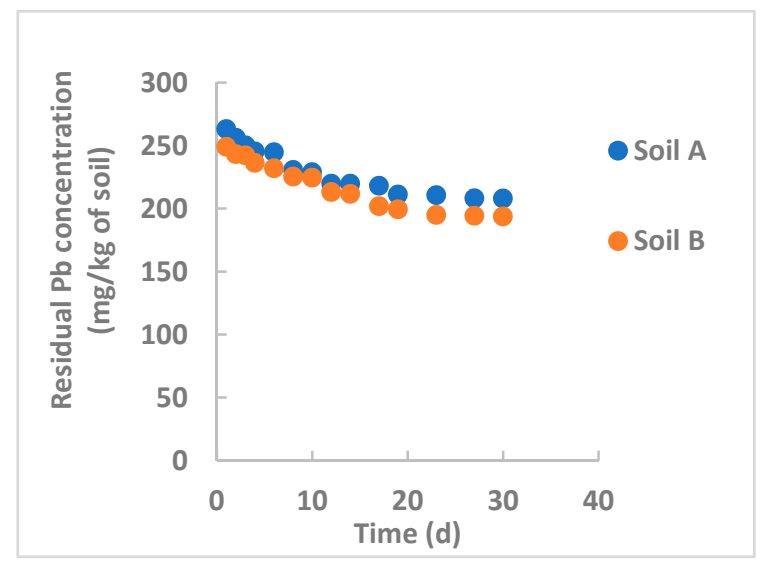

(a)

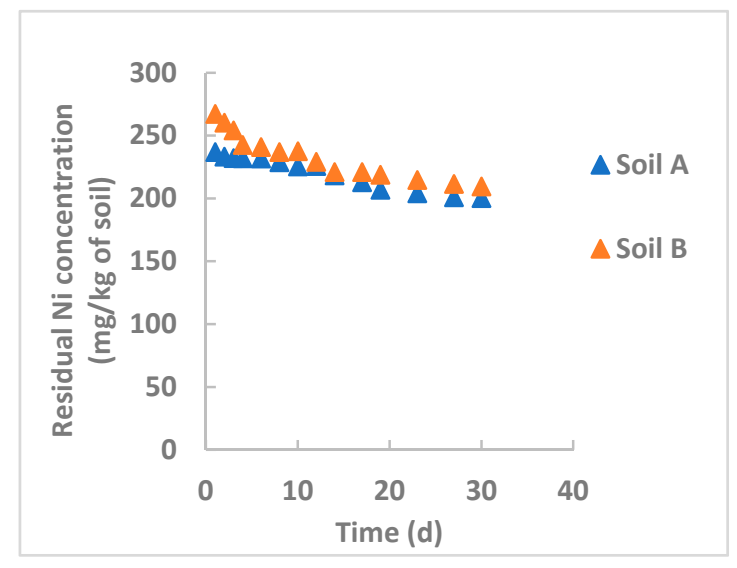

(b)

Figure 3. Remediation of contaminated soil using chemically synthesized nZVI particles (dosage: $0.1 \mathrm{~g} / \mathrm{kg}$ of soil): (a) lead removal; (b) nickel removal.

Considering the system heterogeneity, the experimental data show similar values for the tested soil samples, and on this basis, the heavy metal removal efficiency was calculated as the average value at the end of the experimental run.

After 30 days and with a particle dosage of $0.1 \mathrm{~g} / \mathrm{kg}$ of soil, the $\mathrm{Pb}$ removal efficiency was $21.6 \%$ and $18.5 \%$ for nickel. It can be observed that in any instance, the contaminant removal efficiency of the nanoparticle is low. This finding could be due to aggregation and/or oxidation of nanoparticles. In general, oxidation of the outer layer of the nanoparticle is mainly due to contact with air, which shrinks the adsorption capability of the nanoparticle. This hypothesis is supported by the SEM and TEM analyses. The SEM images show that the nanoparticles are aggregated, which reduces the surface area of the particle. The TEM images indicate the oxidation of the outer layer of nanoparticles. 


\subsubsection{Remediation by nZVI Particles Synthesized Using Neem Leaves}

The nZVI particles synthesized using neem leaves were tested in the same conditions as the chemically synthesized particles, and the experimental results are shown in Figure 4.

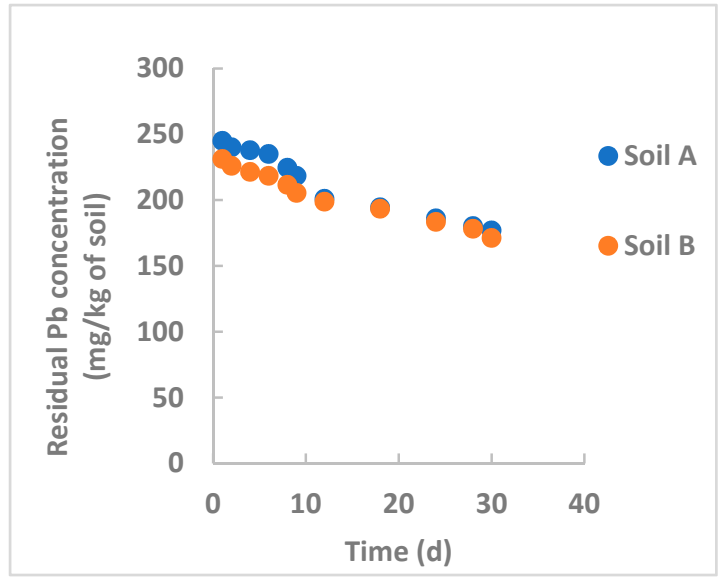

(a)

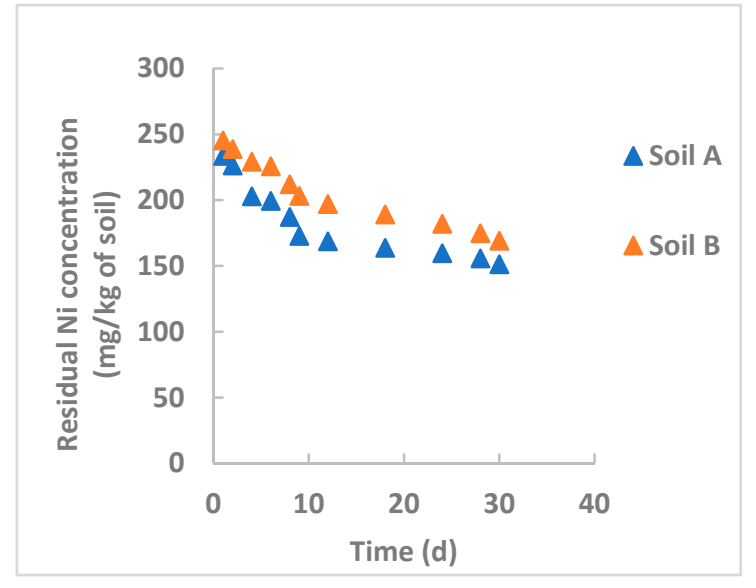

(b)

Figure 4. Remediation of nZVI particles synthesized using neem leaves (dosage: $0.1 \mathrm{~g} / \mathrm{kg}$ of soil):

(a) lead removal; (b) nickel removal.

Figure $4 \mathrm{a}, \mathrm{b}$ shows the residual lead and nickel concentration, respectively, along with the tests with Soils A and B at a dosage of $0.1 \mathrm{~g}$ of neem synthesized nZVI/kg of soil.

Regarding the chemically synthesized particles, Soils A and B performed similarly. After 30 days, the removal efficiency of lead at a dosage of $0.1 \mathrm{~g}$ of neem synthesized nZVI $/ \mathrm{kg}$ of soil was $26.9 \%$, and for nickel, it was $33.2 \%$, demonstrating better performance with nickel than with lead.

After this, it was decided to test double particle dosage with the same initial heavy metal concentration.

Figure 5 depicts the monitoring with $0.2 \mathrm{~g}$ of nZVI particles synthesized using neem leaves per $\mathrm{kg}$ of soil.

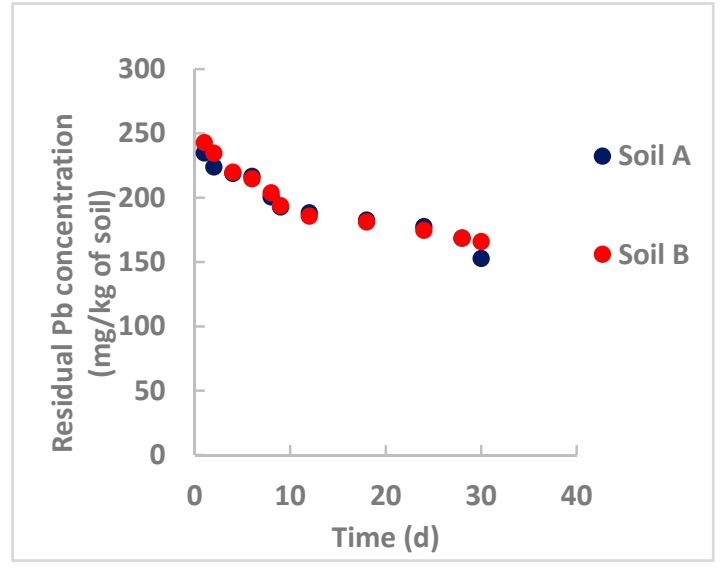

(a)

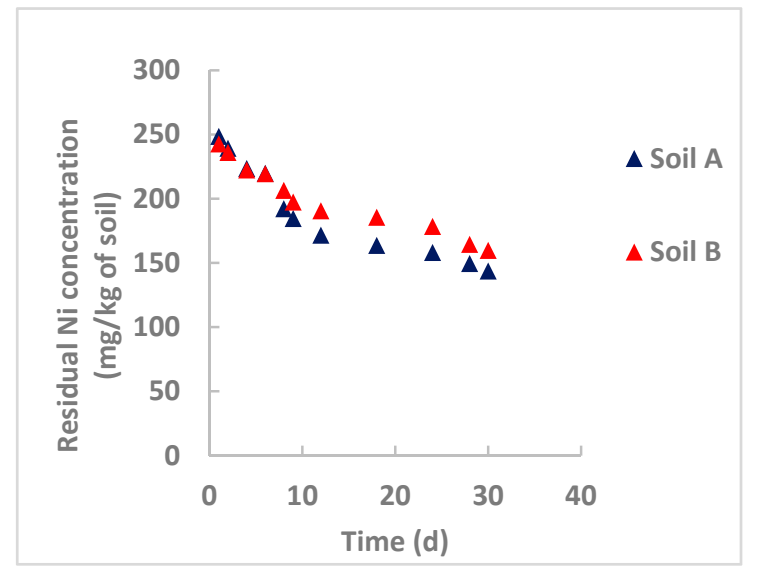

(b)

Figure 5. Remediation of nZVI particles synthesized using neem leaves (dosage: $0.2 \mathrm{~g} / \mathrm{kg}$ of soil):

(a) lead removal; (b) nickel removal.

The trend is the same as that achieved with a dosage of $0.1 \mathrm{~g} / \mathrm{kg}$ of soil. The lead and nickel removal efficiency was observed as $33.3 \%$ and $38.2 \%$, respectively. Comparing these values to lower values, it is evident that the improvement is limited in the order of $24 \%$ for lead and $15 \%$ for nickel.

Examining all the findings, the removal efficiency is not high. This could be due to the low surface area measured by the BET analysis. Agglomeration and oxidation of nanoparticles play a vital role in 
the reduction of removal efficiencies, and unfortunately, these phenomena are evidenced by SEM and TEM images, respectively.

\subsubsection{Remediation by nZVI Particles Synthesized Using Mint Leaves}

The particles derived from mint leaves were tested at the same dosage previously used, namely $0.1 \mathrm{~g} / \mathrm{kg}$ of soil. Figure 6 reports the monitoring during the 30-day test.

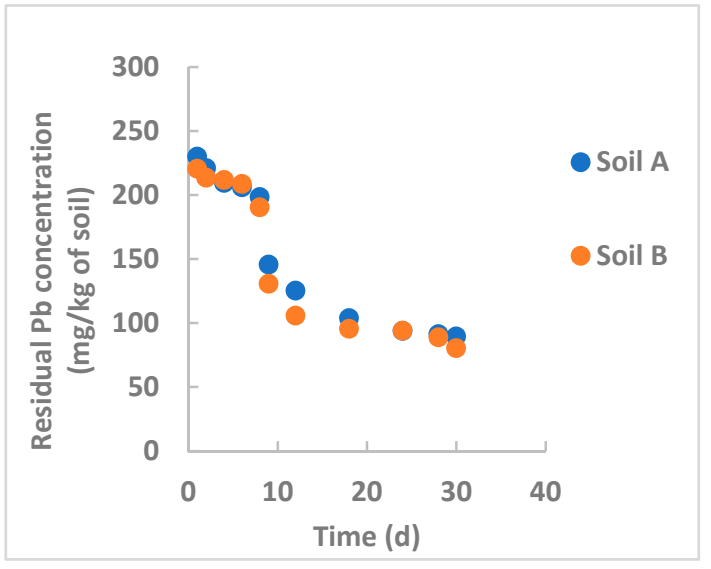

(a)

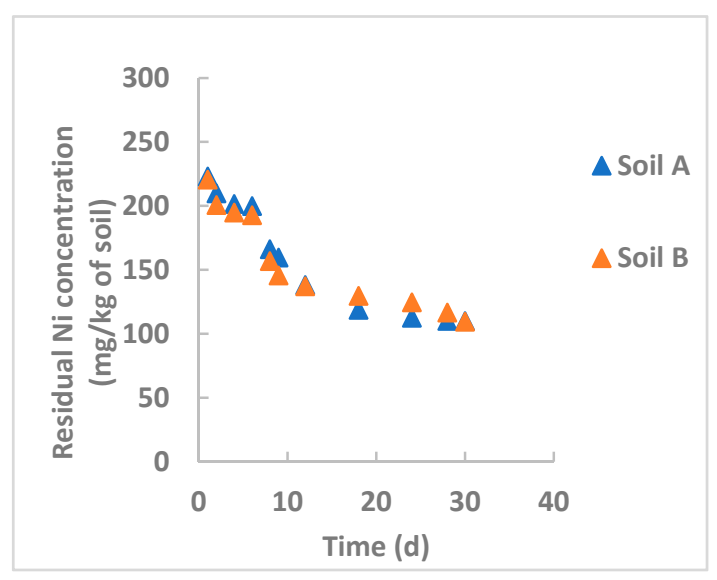

(b)

Figure 6. Remediation of nZVI particles synthesized using mint leaves (dosage: $0.1 \mathrm{~g} / \mathrm{kg}$ of soil): (a) lead removal; (b) nickel removal.

The tested soils behaved similarly, probably due to their similar properties. At the end of the test (after 30 days), the removal efficiency was 62.3\% (lead removal) and 50.6\% (nickel removal).

In this instance, the particles showed better performance with lead than nickel. In both instances, the values were much higher than those with particles derived using neem leaves.

Figure 7 shows the removal efficiency at a doubled dosage of particles derived using mint leaves $(0.2 \mathrm{~g} / \mathrm{kg}$ of soil).

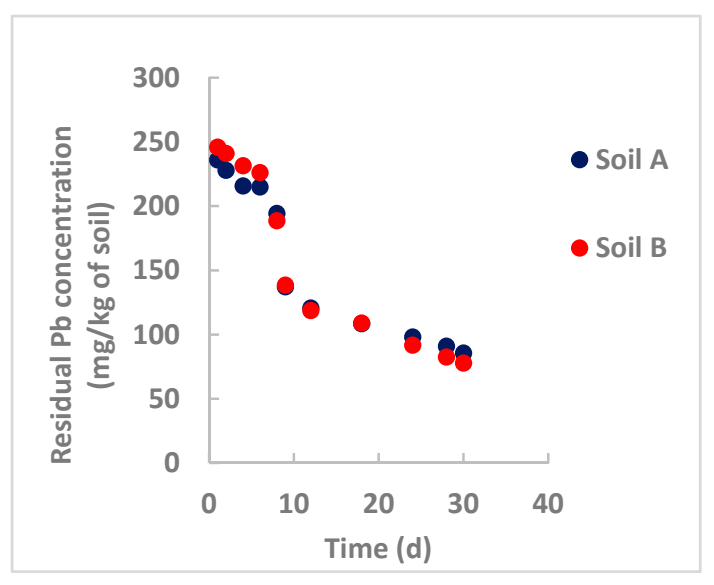

(a)

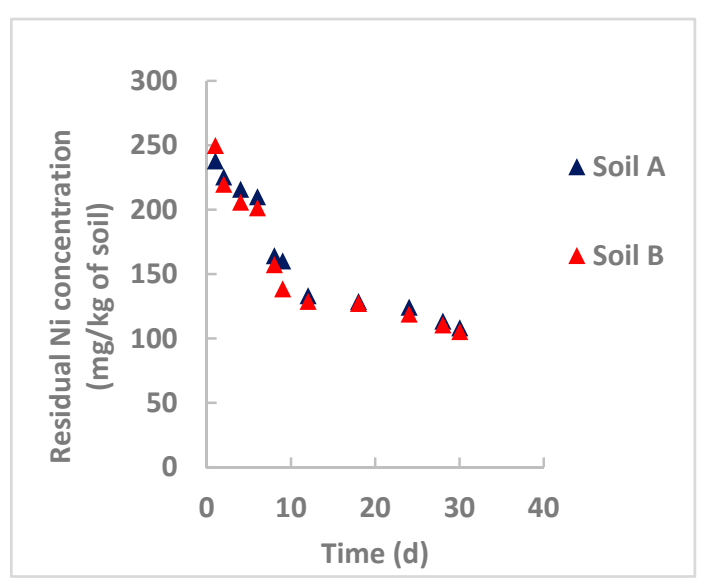

(b)

Figure 7. Remediation of nZVI particles synthesized using mint leaves (dosage: $0.2 \mathrm{~g} / \mathrm{kg}$ of soil): (a) lead removal; (b) nickel removal.

The experimental data do not show relevant differences between the tested soils.

The removal efficiency was higher for lead than nickel, confirming the trend achieved with a lower dosage. After 30 days, $66.1 \%$ of the initial lead and $56.1 \%$ of the initial nickel was removed. 
One reason for the better performance of particles synthesized using mint leaves could be the agglomeration, which is comparatively less than for neem-derived particles, and hence, their surface area is higher than for neem-derived particles (Figure 1).

When the particles were oxidized on their outer surface, the oxidation rate was lower than that of the chemically synthesized particles, as can be observed from the TEM images (Figure 2).

\section{Discussion}

This study aimed to provide preliminary results about the performance of nZVI particles derived using green leaves to remediate heavy-metal-polluted soil. At the same time, chemically synthesized nanoparticles were prepared to compare their removal efficiency to those achievable by vegetal-origin nanoparticles. As leaves, Azadirachta indica (neem) and Mentha longifolia (mint) were chosen.

The targeted heavy metals were lead and nickel.

For a rational discussion and comparison easiness, the results for removal efficiency are summarized in Table 2.

Table 2. The heavy metal removal efficiency of the tested nZVI particles.

\begin{tabular}{ccccc}
\hline Particle Origin & Pb Removal Efficiency at $\mathbf{t}=\mathbf{3 0}$ days & Ni Removal Efficiency at $\mathbf{t}=\mathbf{3 0}$ days \\
\hline \multicolumn{4}{c}{ Particle dosage } \\
\hline Chemically synthesized & $0.1 \mathrm{~g} / \mathrm{kg}$ of soil & $0.2 \mathrm{~g} / \mathrm{kg}$ of soil & $0.1 \mathrm{~g} / \mathrm{kg}$ of soil & $0.2 \mathrm{~g} / \mathrm{kg}$ of soil \\
Neem leaves & $21.6 \%$ & $18.5 \%$ & $38.2 \%$ \\
Mint leaves & $26.9 \%$ & $33.3 \%$ & $33.2 \%$ & $56.1 \%$ \\
\hline
\end{tabular}

By these values, some conclusions can be evidenced:

- The chemically synthesized particles provided the lowest efficiencies.

- The particles achieved by the processing of mint leaves showed the best results for the removal of both the metals.

- With identical nanoparticles dosage, the removal of lead by all the tested particles was constantly higher than nickel, suggesting a higher affinity of the particle for the metal.

- A double dosage improved the removal, albeit to a small extent (the maximum improvement was $26 \%$ for lead removal by neem-derived particles).

To summarize, the ZVI nanoparticles synthesized using green leaves demonstrated a good performance to remove lead and nickel from polluted soil, better than those obtained from chemical synthesis.

To this purpose, different particle properties could play opposite roles. The chemically synthesized particles showed higher BET surface area of approximately 15 against $6-13 \mathrm{~m}^{2} / \mathrm{g}$ of the others. Therefore, the adsorption should occur to a larger extent. However, as a consequence of this property, they were also highly subjected to oxidation, as shown by the TEM images, reducing their removal efficiency.

Examining the residual heavy metal concentration, when chemically synthesized particles were adopted, a decreasing trend was continuous, whereas in the other tests, two-step process could be identified: the first one, lasting about 8-10 days, with a drastic decrease of residual concentration, followed by further removal at a slower rate until the end of the test.

A similar trend was found by other authors:

- Gil-Diaz et al. [32] studied in-field brownfield remediation polluted with arsenic and mercury using commercial nZVI particles for long times (32 months) and achieved an initial sharp reduction of the pollutants, followed by a rather constant residual concentration probably due to interferences of organic matter that can form stable complexes on the particle surface, especially at acidic $\mathrm{pH}$ and limiting the particle removal efficiency. Examining Figures 3-5, this occurs for nickel 
removal in Soil B, where $\mathrm{pH}$ is moderately acidic (5.32) and the organic matter content is high (about 5\%). This is evident for nickel, whereas the $\mathrm{pH}$ influence is not appreciable for lead. One hypothesis can be the different solubility product constant, $\mathrm{K}_{\mathrm{PS}}$, for $\mathrm{Ni}(\mathrm{OH})_{2}$ and $\mathrm{Pb}(\mathrm{OH})_{2}$, which is equal to $6 \times 10^{-16}$ and $1.4 \times 10^{-20}$, respectively. A rough calculation can provide the saturation concentration of the heavy metals at the tested $\mathrm{pH}$ values. For lead, at saturation its concentration is lower than the initial concentration in both instances. Therefore, lead hydroxide also precipitates at an acidic $\mathrm{pH}$. Heavy metal removal by nZVI particles is not only based on precipitation. For lead, this phenomenon could be more influential than the others (adsorption, coprecipitation, oxidation/reduction);

- Mystrioti et al. [33] studied the reduction of hexavalent chromium to Cr(III) by nZVI particles synthesized from several sources, namely Camellia sinensis (green tea), Syzygium aromaticum (clove), Mentha spicata (spearmint), Punica granatum juice (pomegranate), and red wine. The process was conducted on a liquid solution containing $50 \mathrm{mg} / \mathrm{L}$ of $\mathrm{Cr}(\mathrm{VI})$ in contact with different nanoparticle concentrations from the aforementioned sources. The reduction process, occurring on the particle surfaces, had better efficiency at a high particle concentration, and when a low concentration was used, the process kinetics clearly showed two different rates.

- Di Palma et al. [34] used chemically synthesized nZVI particles to reduce $\mathrm{Cr}$ (VI) to $\mathrm{Cr}$ (III) from neutral soil in the slurry mode. Their trials also showed that the reduction efficiency was influenced positively by the test duration and nZVI particle concentration, with a more evident two-step process at a low nZVI particle concentration.

- Wang et al. [35] synthesized nZVI particles from green tea and eucalyptus leaves to remove nitrate from wastewater and compared their performance to the results achieved with particles from chemical synthesis. The best results were achieved with the nanoparticles of chemical origin. However, after air contact for two months, the vegetal-origin nanoparticles did not change their performance and showed good stability, whereas for the others, the removal efficiency dropped by $50 \%$.

From this, it is evident that the findings of the present study are widely supported by similar studies, even if performed with different operative conditions of pollutants, particle origin, and concentration, soil properties, etc.

These findings also evidence the need to continue the study and clarify the many features still pending to apply the process optimally and achieve high efficiency in sustainable terms.

Author Contributions: Conceptualization, S.S.; methodology, S.S. and Y.R.S.; validation, S.S.; formal analysis, S.S. and F.C.; investigation, N.F.; resources, S.S.; writing—original draft preparation, S.S.; writing-review and editing, S.S. and F.C.; supervision, S.S. All authors have read and agreed to the published version of the manuscript.

Funding: This research received no external funding.

Acknowledgments: The first author (N.F.) acknowledges the financial support provided by The Institution of Engineers (India), Kolkata, India under the R \& D Grant-in-aid Scheme (Grant No. RDPG2016004).

Conflicts of Interest: The authors declare no conflict of interest.

\section{References}

1. Kabata-Pendias, A.; Pendias, H. Trace Metals in Soils and Plants; CRC Press: Boca Raton, FL, USA, 2001.

2. Usha, R.; Vasavi, A.; Thishya, K.; Janshi Rani, S.; Supraja, P. Phytoextraction of lead from industrial effluents by sunflower (Helianthus Annuus. L). Rasayan J. Chem. 2011, 4, 8-12.

3. Burke, D.M.; Morris, M.A.; Holmes, J.D. Chemical oxidation of mesoporous carbon foams for lead ion adsorption. Sep. Purif. Technol. 2013, 104, 150-159. [CrossRef]

4. National Safety Council. Lead Poisoning. Available online: https://www.nsc.org/new_resources/\%20resources/ document/lead_poisoning (accessed on 18 November 2015). 
5. $\quad$ Özcan, A.S.; Tunali, S.; Akar, T.; Özcan, A. Biosorption of Lead (II) ions onto waste biomass of Phaseolus vulgaris L.: Estimation of the equilibrium, kinetic and thermodynamic parameters. Desalination 2009, 244, 188-198. [CrossRef]

6. Wuana, R.A.; Okieimen, F.E. Heavy metals in contaminated soils: A review of sources, chemistry, risk and best, available strategies for remediation. ISRN Ecol. 2011. ID 402647. [CrossRef]

7. Dudka, S.; Miller, W.P. Permissible concentration of arsenic and lead in soils based on risk assessment. Water Air Soil Pollut. 1999, 113, 127-132. [CrossRef]

8. Akhtar, N.; Iqbal, J.; Iqbal, M. Removal and recovery of nickel (II) from aqueous solution by loofa sponge-immobilized biomass of Chlorella sorakiniana: Characterisation study. J. Hazard. Mater. 2004, B108, 85-94. [CrossRef]

9. Farooq, U.; Kozinski, J.A.; Khan, M.A.; Athar, M. Biosorption of heavy metal ions using wheat-based biosorbents: A review of the recent literature. Bioresour. Technol. 2010, 101, 5034-5043. [CrossRef]

10. Senthil Kumar, P.S.; Ramalingam, S.; Dinesh Kirupha, S.; Murugesan, A.; Vidhyadevi, T.; Sivanesan, S. Adsorption behaviour of nickel (II) onto cashew nut shell: Equilibrium thermodynamics, kinetics, mechanism and process design. Chem. Eng. J. 2011, 167, 122-131. [CrossRef]

11. Malamis, S.; Katsou, E. A review on zinc and nickel adsorption on natural and modified zeolite, bentonite and vermiculite: Examination of process parameters, kinetics and isotherms. J. Hazard. Mater. 2013, 252-253, 428-461. [CrossRef]

12. Adriano, D.C. Trace Elements in Terrestrial Environment; Springer: New York, NY, USA, 2001.

13. Iyaka, Y.A. Nickel in soils: A review of its distribution and impacts. Sci. Res. Essays 2011, 6, 6774-6777.

14. Basta, N.T.; Gradwohl, R. Remediation of heavy metals contaminated soil using rock phosphate. Better Crops 1998, 82, 29-31.

15. Kuiken, T. Cleaning up contaminated waste site: Is nanotechnology the answer? Nano Today 2009, 5, 6-8. [CrossRef]

16. Pasinszki, T.; Krebsz, M. Synthesis and Application of Zero-Valent Iron Nanoparticles in Water Treatment, Environmental Remediation, Catalysis, and Their Biological Effects. Nanomaterials 2020, 10, 917. [CrossRef]

17. Bhattacharya, S.; Saha, I.; Mukhopadhyay, A.; Chattopadhyay, D.; Gosh, U.; Chatterjee, D. Role of nanotechnology in water treatment and purification: Potential applications and implications. Int. J. Chem. Sci. Technol. 2013, 3, 59-64.

18. Liao, C.J.; Chung, T.L.; Chen, W.L.; Kuo, S.L. Treatment of pentachlorophenol-contaminated soil using nano-scale zero-valent iron with hydrogen peroxide. J. Mol. Catal. A Chem. 2006, 265, 189-194. [CrossRef]

19. Taghipour, M.; Jalali, M. Effect of clay minerals and nanoparticles on chromium fractionation in soil contaminated with leather factory waste. J. Hazard. Mater. 2015, 297, 127-133. [CrossRef]

20. Allabaksh, M.B.; Mandal, B.K.; Kesarla, M.K.; Kumar, K.S.; Reddy, P.S. Preparation of stable Zero Valent Iron nanoparticles using different chelating agents. J. Chem. Pharm. Res. 2010, 2, 67-74.

21. Valipour, M.; Shahbazi, K.; Khanmirzaei, A. Chemical immobilization of lead, cadmium, copper, and nickel in contaminated soils by phosphate amendments. CLEAN Soil Air Water 2016, 44, 572-578. [CrossRef]

22. Yadegari, M. Performance of purslane (Portulaca oleracea) in nickel and cadmium contaminated soil as a heavy metals-removing crop. Iran. J. Plant Physiol. 2018, 8, 2447-2455.

23. De Gisi, S.; Minetto, D.; Lofrano, G.; Libralato, G.; Conte, B.; Todaro, F.; Notarnicola, M. Nano-scale zero valent iron (nZVI) treatment of marine sediments slightly polluted by heavy metals. Chem. Eng. Trans. 2017, 60, 139-144.

24. Vasarevičius, S.; Danila, V.; Paliulis, D. Application of stabilized nano Zero Valent Iron particles for immobilization of available $\mathrm{Cd}^{2+}, \mathrm{Cu}^{2+}, \mathrm{Ni}^{2+}$, and $\mathrm{Pb}^{2+}$ ions in soil. Int. J. Environ. Res. 2019, 13, 465-474. [CrossRef]

25. Pattanayak, M.; Nayak, P.L. Green synthesis and characterisation of Zero Valent Iron nanoparticles from leaf extract of Azadirachta Indica (Neem). World J. Nano Sci. Technol. 2013, 2, 6-9.

26. IS:3025-Part 11, Methods of Sampling and Test (Physical and Chemical) for Water and Wastewater, Part 11 pH Value; Bureau of Indian Standards: New Delhi, India, 2006.

27. IS:3025-Part 14, Methods of Sampling and Test (Physical and Chemical) for Water and Wastewater, Part 14 Specific Conductance; Bureau of Indian Standards: New Delhi, India, 2002.

28. ASTM D854, Standard Test Methods for Specific Gravity of Soil Solids by Water Pycnometer; ASTM International: West Conshohocken, PA, USA, 2014. 
29. ASTM D4959, Standard Test Method for Determination of Water Content of Soil by Direct Heating; ASTM International: West Conshohocken, PA, USA, 2016.

30. ASTM D2974, Standard Test Methods for Moisture, Ash, and Organic Matter of Peat and Other Organic Soils; ASTM International: West Conshohocken, PA, USA, 2014.

31. ASTM D422, Standard Test Method for Particle-Size Analysis of Soils; ASTM International: West Conshohocken, PA, USA, 2007.

32. Gil-Díaz, M.; Rodríguez-Valdés, E.; Alonso, J.; Baragaño, D.; Gallego, J.R.; Lobo, M.C. Nanoremediation and long-term monitoring of brownfield soil highly polluted with As and Hg. Sci. Total Environ. 2019, 675, 165-175. [CrossRef]

33. Mystrioti, C.; Xanthopoulou, T.D.; Tsakiridis, P.; Papassiopi, N.; Xenidis, A. Comparative evaluation of five plant extracts and juices for nanoiron synthesis and application for hexavalent chromium reduction. Sci. Total Environ. 2016, 539, 105-113. [CrossRef]

34. Di Palma, L.; Gueye, M.T.; Petrucci, E. Hexavalent chromium reduction in contaminated soil: A comparison between ferrous sulphate and nanoscale zero-valent iron. J. Hazard. Mater. 2015, 281, 70-76. [CrossRef]

35. Wang, T.; Lin, J.; Chen, Z.; Megharaj, M.; Naidu, R. Green synthesized iron nanoparticles by green tea and eucalyptus leaves extracts used for removal of nitrate in aqueous solution. J. Clean. Prod. 2014, 83, 413-419. [CrossRef]

Publisher's Note: MDPI stays neutral with regard to jurisdictional claims in published maps and institutional affiliations. 